\title{
Weaning failure of cardiovascular origin: how to suspect, detect and treat-a review of the literature
}

\author{
Christina Routsi ${ }^{* *}$, Ioannis Stanopoulos ${ }^{2}$, Stelios Kokkoris ${ }^{1}$, Antonios Sideris ${ }^{3}$ and Spyros Zakynthinos ${ }^{1}$
}

\begin{abstract}
Among the multiple causes of weaning failure from mechanical ventilation, cardiovascular dysfunction is increasingly recognized as a quite frequent cause that can be treated successfully. In this review, we summarize the contemporary evidence of the most important clinical and diagnostic aspects of weaning failure of cardiovascular origin with special focus on treatment. Pathophysiological mechanisms are complex and mainly include increase in right and left ventricular preload and afterload and potentially induce myocardial ischemia. Patients at risk include those with preexisting cardiopulmonary disease either known or suspected. Clinically, cardiovascular etiology as a predominant cause or a contributor to weaning failure, though critical for early diagnosis and intervention, may be difficult to be recognized and distinguished from noncardiac causes suggesting the need of high suspicion. A cardiovascular diagnostic workup including bedside echocardiography, lung ultrasound, electrocardiogram and biomarkers of cardiovascular dysfunction or other adjunct techniques and, in selected cases, right heart catheterization and/or coronary angiography, should be obtained to confirm the diagnosis. Official clinical practice guidelines that address treatment of a confirmed weaning-induced cardiovascular dysfunction do not exist. As the etiologies of weaning-induced cardiovascular dysfunction are diverse, principles of management depend on the individual pathophysiological mechanisms, including preload optimization by fluid removal, guided by B-type natriuretic peptide measurement, nitrates administration in excessive afterload and/or myocardial ischemia, contractility improvement in severe systolic dysfunction as well as other rational treatment in specific indications in order to lead to successful weaning from mechanical ventilation.
\end{abstract}

Keywords: Weaning from mechanical ventilation, Weaning-induced cardiovascular dysfunction, Cardiovascular drug therapy, Intensive care, Difficult-to-wean patients

\section{Introduction}

Among the many causes and pathophysiological mechanisms that impair weaning from mechanical ventilation $[1,2]$, the respiratory system failure is considered to be the most common, typically viewed as an imbalance between respiratory load and respiratory muscle capacity [3-5]. Cardiovascular dysfunction as an underlying mechanism of weaning failure, though initially described in 1988 by Lemaire et al. in patients with chronic

\footnotetext{
*Correspondence: chroutsi@hotmail.com; chroutsi@med.uoa.gr ${ }^{1}$ First Department of Critical Care, Medical School, National and Kapodistrian University of Athens, "Evangelismos" Hospital, Ipsilantou 45-47, 10676 Athens, Greece

Full list of author information is available at the end of the article
}

obstructive pulmonary disease (COPD) and concomitant cardiovascular disease [6] was rather underestimated over the next decade. In 2002, the term "weaninginduced cardiac failure" was introduced [7]. Since then, this condition has become more recognizable, but its true incidence is unknown. In an earlier study, Epstein et al. [8] found that as many as one-third of weaning failures resulted solely or in part from "congestive heart failure." An even higher prevalence of weaning-induced cardiovascular dysfunction has been reported from experienced centers where this condition is systematically examined [9-13]. Therefore, this entity is currently deemed to be common, particularly in specific subgroups of mechanically ventilated patients such as those with COPD and/or underlying cardiac disease $[6,11-15]$. 
Despite the significant advances in understanding the pathophysiology of weaning failure of cardiovascular origin, studies demonstrating improved weaning outcomes by appropriate treatment are scarce $[6,16-21]$. However, despite the lack of adequate evidence demonstrating benefit, in daily clinical practice ICU clinicians caring for mechanically ventilated patients with difficult weaning of cardiovascular origin, frequently make treatment decisions by using pharmacotherapies mainly adopted from the evidence-based non-ICU cardiology.

We conducted a literature review to summarize earlier and contemporary evidence of the most important clinical and diagnostic aspects of cardiovascular origin weaning failure with special focus on treatment.

\section{Pathophysiological considerations}

Knowledge of the changes in the cardiopulmonary pathophysiology that occur during mechanical ventilation and its withdrawal $[22,23]$, is a prerequisite for early recognition of weaning failure of cardiovascular origin and optimal patient management. The success of weaning depends on the ability of the respiratory system and cardiac pump to tolerate these changes.

Earlier studies, both experimental and clinical [6, 2426], give convincing evidence of acute cardiovascular dysfunction as the origin or a cofactor of weaning failure. Briefly, mechanical ventilation with positive airway and intrathoracic pressures reduces venous return and both left ventricular (LV) preload and afterload [22]. On the contrary, the shift from mechanical ventilation to spontaneous breathing induces: first, a negative intrathoracic pressure which, (a) increases the systemic venous return pressure gradient, the right ventricular preload, the central blood volume and the LV preload and (b) increases the surrounding pressure of the LV with a resulting increase in LV afterload; second, an increase in the work of breathing, and, third, an increase in adrenergic tone as documented by an increase in serum catecholamine levels $[6,27]$. These main three triggering mechanisms may induce cardiovascular dysfunction clinically expressed by (i) an increase in pulmonary arterial occlusion pressure (PAOP), (ii) increase in LV filling pressure and finally (iii) pulmonary edema. Figure 1, (adapted from [14]), clearly describes the main mechanisms potentially involved in the development of weaning-induced pulmonary edema. These acute hemodynamic effects may have detrimental consequences in patients with cardiovascular disease. Particularly in those patients with coronary artery disease, they may induce localized myocardial ischemia or unmask areas of preexisting marginal function [28]. It is worth noting that mitral regurgitation has been described during failed weaning in the presence of

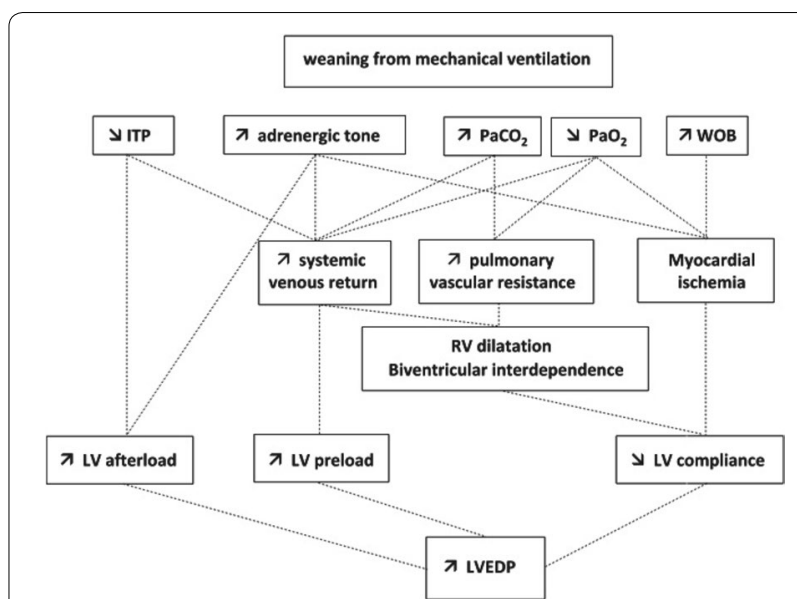

Fig. 1 Main mechanisms potentially involved in the development of weaning-induced pulmonary edema. ITP intrathoracic pressure, $L V$ left ventricular, $L V E D P$ left ventricular end-diastolic pressure, $\mathrm{PaO}_{2}$ oxygen arterial pressure, $\mathrm{PaCO}_{2}$ carbon dioxide arterial pressure, $\mathrm{RV}$ right ventricular, WOB work of breathing (adapted from [14])

myocardial ischemia $[16,29,30]$, further worsening the cardiovascular dysfunction.

Cardiovascular dysfunction during weaning process may involve systolic and/or diastolic LV alterations [11-13, 31-34]. Recent findings emphasize the role of LV diastolic dysfunction with preserved LV contractility as a contributor to weaning failure. Among ICU patients admitted for other reasons than those related to cardiac disease, weaning failure was more frequently due to varying degrees of LV diastolic than systolic dysfunction [33].

\section{Identification of patients at high risk of weaning failure of cardiovascular origin}

Clinically, cardiovascular etiology as a predominant or a contributing factor to weaning failure can be difficult to distinguish from other causes of weaning failure for two reasons: first, this entity may exist at a subclinical level, i.e., some patients may have an almost normal resting cardiovascular function and conditions of increased oxygen demand and consumption, such as a stressful spontaneous breathing trial (SBT), could unmask an underlying cardiovascular dysfunction. Second, both subjective (such as discomfort, dyspnea, anxiety) and objective (tachypnea, tachycardia, wheezing, hypoxemia, hypercapnia) criteria for weaning failure are nonspecific and usually incapable of discriminating cardiac from noncardiac causes of weaning failure [35]. Therefore, weaning failure of cardiovascular origin may be underdiagnosed, and, thus, undertreated due to lack of clinical suspicion.

Classical risk factors for weaning failure of cardiovascular origin mainly include a preexisting cardiopulmonary disease that is either known or suspected [11, 12, 32]. Since, COPD and ischemic heart disease have 
common risk factors [36, 37], cardiovascular-related weaning failure should be suspected primarily in patients with COPD under mechanical ventilation and presenting difficult weaning. Obviously, the presence of COPD does not identify with certainty a cardiovascular origin of weaning failure. Other causes, e.g., inadequate pharmacological control of the disease, hyperinflation and/ or respiratory muscle dysfunction leading to respiratory pump failure must be considered as well.

Silent cardiovascular dysfunction in mechanically ventilated patients with a history of pulmonary disease has been increasingly detected. In a recent study including 107 mechanically ventilated patients with severe exacerbation of COPD, unrecognized previous heart failure was common [38]. Interestingly, the early detection and treatment of heart failure according to current guidelines [39], including administration of diuretics, angiotensin-converting enzyme inhibitors or selective $\beta 1$-blockers, shortened the length of mechanical ventilation and ICU stay and decreased hospital mortality, indicating the effectiveness of appropriate treatment on the outcome.

In a study of extubation failure [40], a subset of patients with high risk of re-intubation was identified, including those over 65 years old and/or having underlying cardiac or respiratory disease, whereas other factors such as disease severity, mechanical ventilation duration, or arterial blood gases values were not significant. Similarly, previous COPD and "cardiopathy" were factors that were independently associated with weaning-induced pulmonary edema [12]. In another study among nonselected mechanically ventilated patients, Caille et al. [11] observed a high incidence of weaning failure of cardiovascular origin in a subset of patients who failed to wean. Compared to those who succeeded, patients who failed had a significantly lower LV ejection fraction and higher filling pressures before the start of SBT, underlining the contribution of LV systolic dysfunction to weaning failure. Similarly, severe systolic LV dysfunction was an independent factor for extubation failure in a recent study [32]. In summary, in clinical practice, in any unexpected difficulty in weaning, the possibility of an underlying cardiovascular dysfunction should be raised, provided an apparent recovery of adequate respiratory function.

\section{Diagnostic methods to detect cardiovascular dysfunction in patients with difficult weaning}

Upon suspicion of cardiovascular origin of weaning failure, a diagnostic workup should be obtained in order to distinguish between cardiac and noncardiac causes of weaning failure. This kind of evaluation is crucial as it may have direct therapeutic implications. The following part constitutes a brief review of the readily available methods that are considered to confirm a cardiovascularrelated weaning failure (Fig. 2). These methods can be used either alone or in combination.

\section{Pulmonary artery catheterization}

Traditionally, weaning-related cardiovascular dysfunction has been defined as the association of signs of clinical intolerance and a PAOP of $18 \mathrm{mmHg}$ or higher during a SBT $[6,10,41,42]$. Since active expiration due to expiratory muscle contraction is usual during weaning failure, resulting in overestimation of PAOP, the PAOP value should be corrected for this. An esophageal balloon positioning allows pleural pressure measurement to obtain transmural pressure as the difference between PAOP and pleural pressure at expiration $[6,43]$.

Additionally, pulmonary artery catheter permits hemoglobin oxygen saturation of mixed venous blood $\left(\mathrm{SvO}_{2}\right)$ measurement or continuous recording. In fact, patients detected with an increase in PAOP during SBTs, usually experience a substantial decline in $\mathrm{SvO}_{2}$ during SBTs $[44,45]$ that reflects inadequate oxygen delivery for the increased oxygen consumption, indicating, thus, the contribution of cardiovascular dysfunction. These patients have a high likelihood of failure to wean. In contrast, $\mathrm{SvO}_{2}$ usually remains unchanged in patients who are successfully weaned from mechanical ventilation [44]. However, a subset of failed-to-wean patients whose $\mathrm{SvO}_{2}$ does not decrease has been described [45]. These patients do not have increased oxygen consumption during weaning failure, possibly due to respiratory center depression in some of the cases.

Today, pulmonary artery catheters are less commonly used, compared to the past, due to lack of evidence concerning the benefits of right heart catheterization [46]. When cardiovascular origin of weaning failure is suspected, a number of non- or less invasive diagnostic methods are now available [47]. These methods are presented in the following paragraphs.

\section{Critical care echocardiography}

Critical care echocardiography combines transthoracic echocardiography and chest ultrasonography examination which have both been increasingly used to identify noninvasively, at bedside the diagnosis and the mechanism of weaning failure of cardiovascular origin [48].

\section{Transthoracic echocardiography}

In addition to the conventional evaluation of structural and systolic properties of the heart, echocardiography can diagnose diastolic dysfunction by the use of tissue Doppler imaging (TDI). By measurement of the early (E) and late (A) peak diastolic wave velocities at the mitral valve, using pulsed-wave Doppler, and of the early $\left(\mathrm{e}^{\prime}\right)$ 


\section{Suspected weaning failure of cardiovascular origin}

- History; predisposing risk factors:

prior cardiovascular and/or pulmonary disease (mainly COPD)

- Clinical assesment

- Exclude other causes

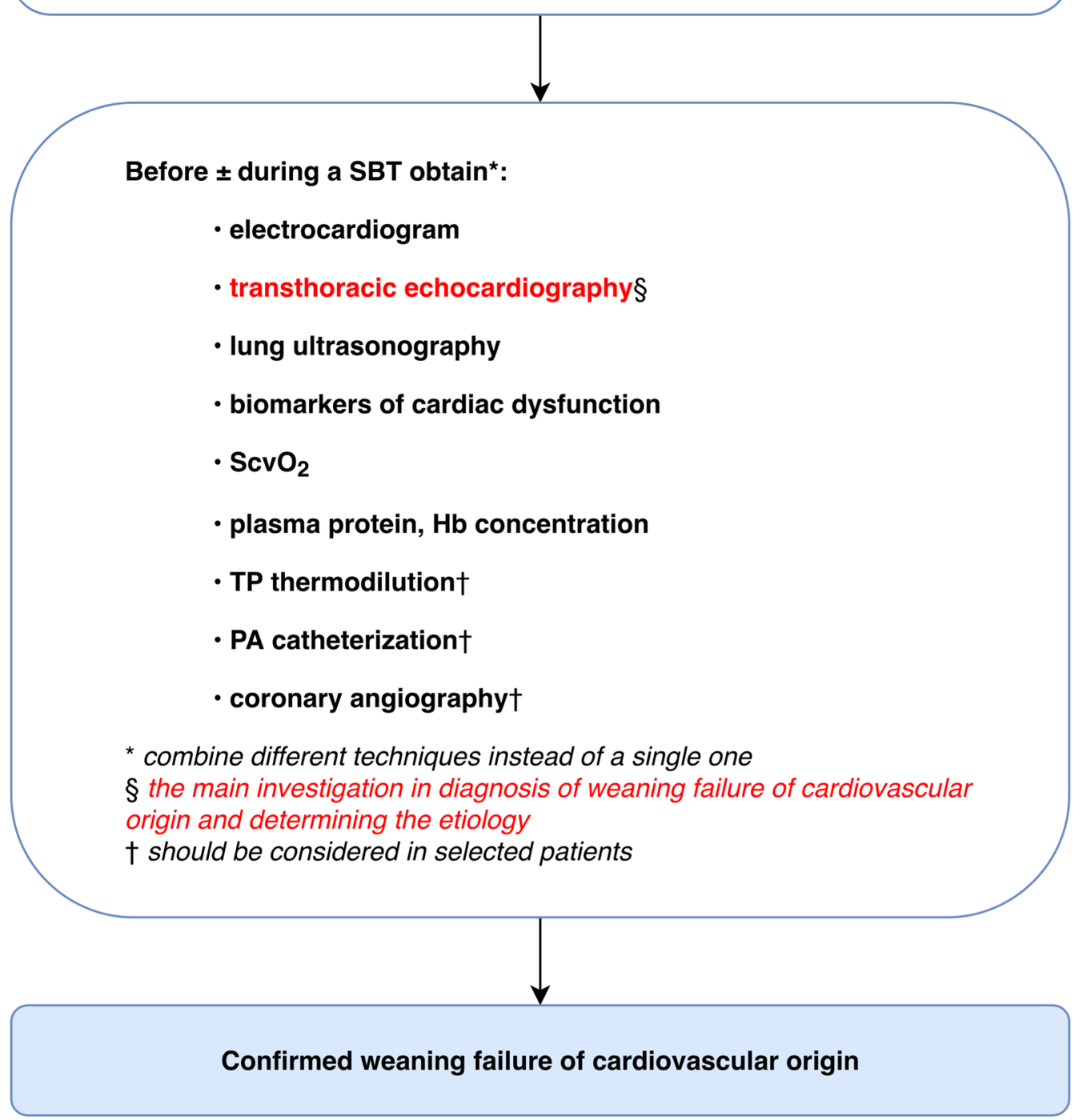

Fig. 2 Workup to detect the cardiovascular origin of weaning failure: a general approach. COPD chronic obstructive pulmonary disease, SBT spontaneous breathing trial, $\mathrm{ScVO}_{2}$ central venous oxygen saturation, TP transpulmonary, PA pulmonary artery, Hb Hemoglobin 
and late $\left(\mathrm{a}^{\prime}\right)$ diastolic wave velocities at the lateral mitral valve annulus by using TDI, echocardiography can reliably demonstrate $\mathrm{LV}$ relaxation ( $\mathrm{e}^{\prime}$ wave) and the grade of LV diastolic dysfunction by calculating the $\mathrm{E} / \mathrm{e}^{\prime}$ ratio [49].

In a selected population of difficult-to-wean patients, Lamia and colleagues found that at the end of a SBT, the combination of $\mathrm{E} / \mathrm{A}>0.95$ and $\mathrm{E} / \mathrm{e}^{\prime}>8.5$ allowed an accurate detection of weaning-induced PAOP elevation associated with LV diastolic dysfunction [50]. Similarly, in other studies, irrespectively of the presence of diastolic dysfunction at rest, echocardiography, performed before the beginning and over the course of a SBT, explored the evolution of LV contractility and relaxation, detecting thus, cardiovascular dysfunction [11, 13, 33, 51-53]. Remarkably, in some studies, a sole TTE performed before conducting the SBT provided early detection of those patients with impaired LV diastolic function, who were at high risk of a subsequent SBT failure [11, 33, 34].

As latent cardiac failure can become evident during stress, a stress echocardiography (using dobutamine to assess diastolic function as well as ephedrine to evaluate functional mitral regurgitation) was recently used to identify stress-related myocardial dysfunction during the weaning period in patients with resolved cardiogenic shock who experienced weaning failure [54]. It was proved helpful in detecting silent diastolic and systolic dysfunction or severe mitral regurgitation that could have a major impact on weaning outcome.

\section{Chest ultrasonography}

Lung ultrasound represents a valuable adjunct for evaluating whether respiratory failure is related to cardiogenic pulmonary edema or not [55]. Mongodi et al. [56] described a case of a patient with an unexpected cardiogenic cause of weaning failure to be uncovered by the combined use of transthoracic echocardiography and lung ultrasound, leading, thus, to subsequent appropriate patient management. On the other hand, combined uses of ultrasonography are highly helpful in ruling out a cardiogenic origin and identifying alternative causes of weaning failure, like diaphragmatic dysfunction [57]. Both established and innovative applications of ultrasonography during the weaning process, including assessment of the heart, the diaphragm, the pleura and the lung have been recently described in an excellent review [58].

In summary, bedside critical care echocardiography is a convenient tool to help in the diagnostic workup of weaning failure of cardiovascular origin. Patient-related factors (poor echocardiographic window, particularly among COPD patients, edema, obesity, surgical dressings and significant valvulopathies that can affect the Doppler parameters), equipment quality and clinical skills remain the main limitations in this setting.

\section{Electrocardiogram}

A low incidence of electrocardiogram (ECG) changes indicating ischemia during weaning has been reported in a general ICU population [59-61]. However, this method suffers from a lack of sensitivity. Indeed, LV wall motion abnormalities occurring or worsening during weaning from mechanical ventilation, detected by myocardial perfusion scintigraphy studies, have been documented without concomitant ECG changes [6, 62].

\section{Biochemical indices of weaning-induced cardiovascular dysfunction}

Biomarkers of the volume status and functional state of the heart including serum B-type natriuretic peptide (BNP) and/or N-terminal (NT)-proBNP, have been used as surrogate markers of cardiovascular dysfunction in patients with difficult weaning. High basal levels of BNP or NT-proBNP $[34,42,63]$ and/or a BNP increase at SBT completion $[10,15,34,42,64,65]$ have been shown to be associated with an increased risk of weaning failure, possibly indicating an underestimated cardiovascular dysfunction. Dres et al., using the pulmonary artery catheter as the reference method, demonstrated that SBT-induced increases in BNP level by more than $12 \%$ allowed detection of increases in PAOP and, therefore, the diagnosis of weaning-induced pulmonary edema contributing to weaning failure, with a sensitivity of $76 \%$ and a specificity of 78\% [10]. Furthermore, a relation between BNP levels and LV diastolic dysfunction grading has been demonstrated in mechanically ventilated patients considered for weaning [34], just like it had been previously shown in patients with heart failure [66]. The short half-life of BNP (22 min) compared with the longer one of NTproBNP $(120 \mathrm{~min})[42,67]$ suggests that BNP measurement should be more relevant in the context of weaning. Moreover, important to note, BNP could be increased in renal impairment, thus, it should be taken into account for the analysis of the BNP plasma kinetics.

\section{Blood volume contraction markers}

An acute increase in plasma protein or hemoglobin concentration, both greater than 5\% during a SBT, reflecting the blood volume contraction induced by pulmonary edema formation has been demonstrated to correlate with the reference diagnostic method, i.e., PAOP increase above $18 \mathrm{mmHg}$, with acceptable diagnostic power [10, 68]. Thus, it has been proposed as an indirect indication of weaning-induced cardiovascular dysfunction. 


\section{Extravascular lung water}

Transpulmonary thermodilution provides direct estimation of pulmonary edema through calculation of the extravascular lung water (EVLW) [69]. The ability of EVLW measurement to detect pulmonary congestion during weaning from mechanical ventilation has been investigated [10]. An increase in indexed EVLW by more than $14 \%$ during SBT was able to diagnose weaninginduced pulmonary edema with a sensitivity of $67 \%$ and a specificity of $100 \%$. However, transpulmonary thermodilution devices are not widely applied during a weaning process, unless they had been previously used and they are still in place.

\section{Passive leg raising}

Passive leg raising (PLR) by 45 degrees is a dynamic test to assess cardiac preload status and fluid responsiveness. By measuring real-time changes in cardiac output, PLR test is considered to be either positive, if cardiac output increases (indicating preload dependence), or negative, if no augmentation of cardiac output occurs (indicating preload independence) [70]. Based on an expected cardiac preload increase during transmission from mechanical ventilation to spontaneous breathing, PLR has been evaluated to assess the risk of weaning-induced cardiovascular dysfunction. It was found that a negative PLR test prior to SBT indicating preload independence, predicted weaning failure due to cardiovascular dysfunction with a sensitivity of $97 \%$ and specificity of $81 \%$ [41].

\section{Treatment strategies in weaning failure of cardiovascular origin}

Since cardiovascular dysfunction could be considered as a modifiable factor of weaning failure, appropriate treatment should be started upon confirmation by using one or more of the aforementioned diagnostic methods. Even if the case of cardiovascular dysfunction is not the sole mechanism of weaning failure, it is probably the only one that could be easily addressed and that with respect to the load capacity respiratory balance, improving even slightly one of its determinants might overall improve patient's outcome.

Large controlled studies systematically investigating the effectiveness of cardiovascular agents and/or other adjuvant treatment to facilitate difficult weaning of cardiovascular origin were not found. However, therapeutic options are available from a limited number of small-sized studies or case studies and case series reports, supporting appropriate treatment to optimize the management of weaning-induced cardiovascular dysfunction. As a result, there are no evidence-based recommendations by international guidelines for the management of weaning failure of cardiovascular origin. However, proposed recommendations by experts including algorithmic approaches have been provided so far $[16,71]$.

Clinical data on the cardiovascular agents that have been used for the treatment of weaning failure are shown in Table 1.

\section{Pharmacological treatments (Fig. 3)}

\section{(1) Fluid management/Volume overload/Diuretics}

Fluid could be considered as a drug that can be overdosed in the ICU. Large volume fluid infusion during initial resuscitation of acute critical illness results in fluid overload and fluid retention, clinically presented as pulmonary and peripheral edema. Negative fluid balance is an expected result of resolution of the pathophysiological process of acute illness and/or the result of an intervention either pharmaceutical, i.e., administration of diuretics, or even renal replacement therapy.

Several studies have shown that fluid overload could be associated with failure to wean from mechanical ventilation $[6,12,72,73]$. The first randomized study to address fluid management during weaning has been reported by Mekontso Dessap et al. [65]. In mechanically ventilated patients who fulfilled criteria for weaning attempts, the authors showed that fluid management strategy guided by daily BNP plasma concentrations, compared to the physician-guided strategy, decreased the duration of weaning without increasing adverse consequences on hemodynamics or renal function. Compared with the control group, the BNP-guided group had a higher proportion of patients receiving diuretics (furosemide and acetazolamide), resulting thus, in a significantly more negative fluid balance. Particularly, the subgroup of patients with LV systolic dysfunction showed the bestpossible beneficial effect of this strategy. Since BNP levels reflect the changes in LV wall stretch and correlate closely with filling pressures in patients with LV dysfunction $[66,74]$, presumably the negative fluid balance prevented cardiac preload increase, thereby protecting these patients from the development of pulmonary edema during weaning. This explanation is further supported by the finding that in other groups of patients, such as pure COPD patients, such beneficial effect was not found, probably because other pathophysiological causes, such as impaired respiratory mechanics leading to increased respiratory load mainly contributed to weaning difficulties [3-5]. In addition, the benefit of PLR-guided fluid removal guided by a PLR test has been shown $[12,41]$. These data actually confirm previous knowledge coming from the landmark study of Lemaire et al. [6], on the 
Confirmed Weaning failure of cardiovascular origin

Determine etiology and start appropriate treatment

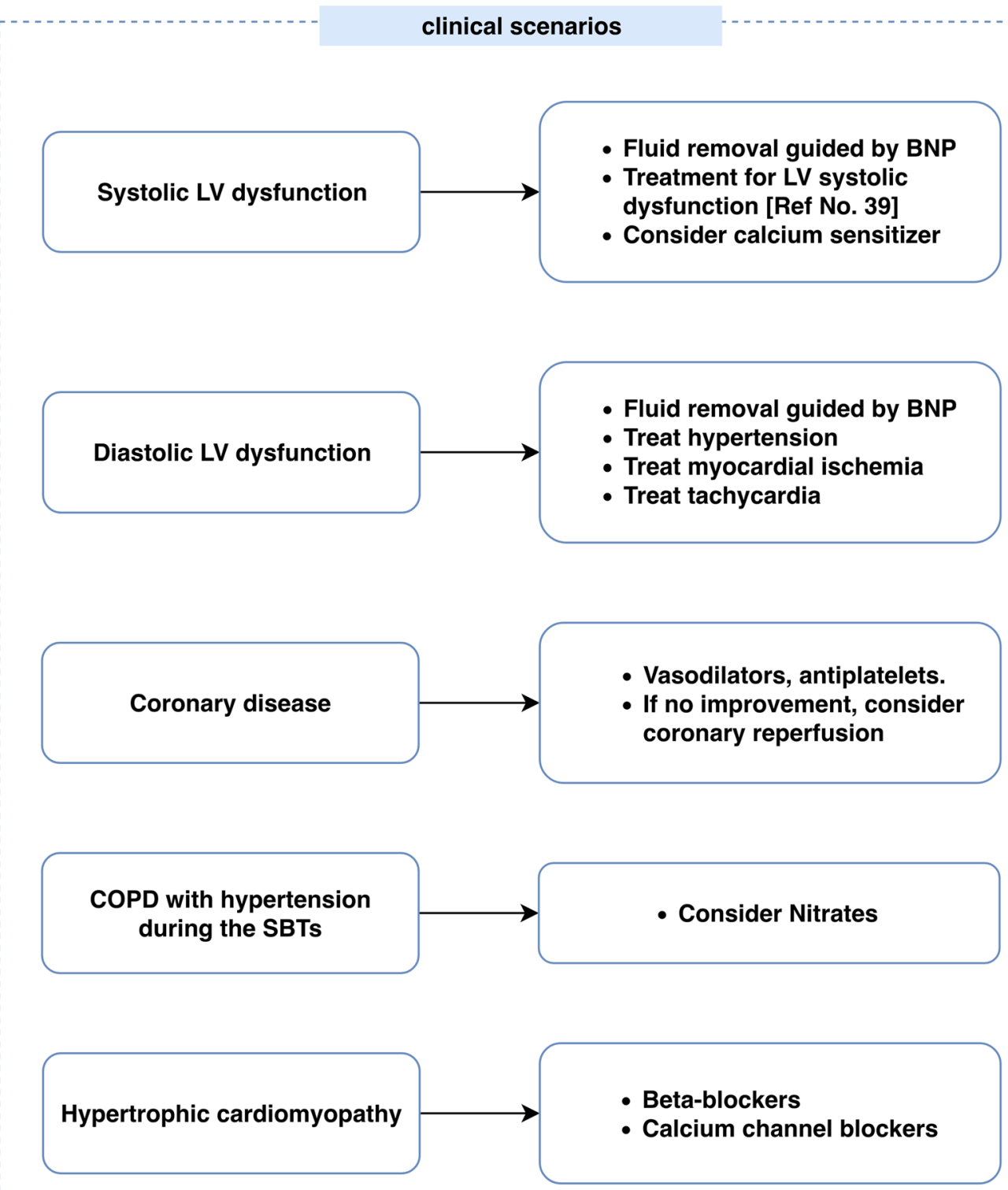

Fig. 3 Suggested treatment for weaning failure of cardiovascular origin, according to the etiology. LV left ventricular, BNP B-type natriuretic peptide, COPD chronic obstructive pulmonary disease, SBT spontaneous breathing trial, ACE angiotensin-converting enzyme 


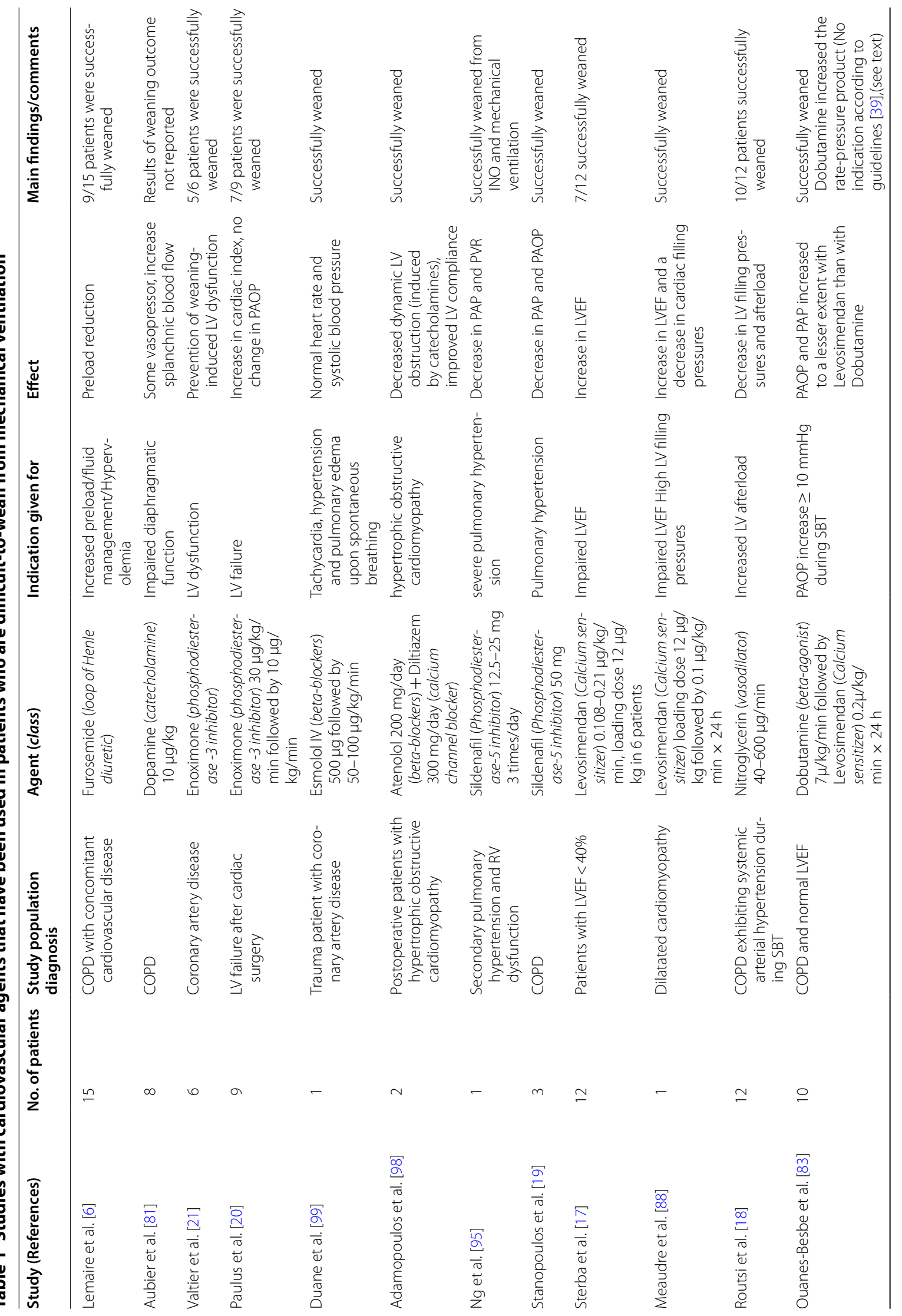




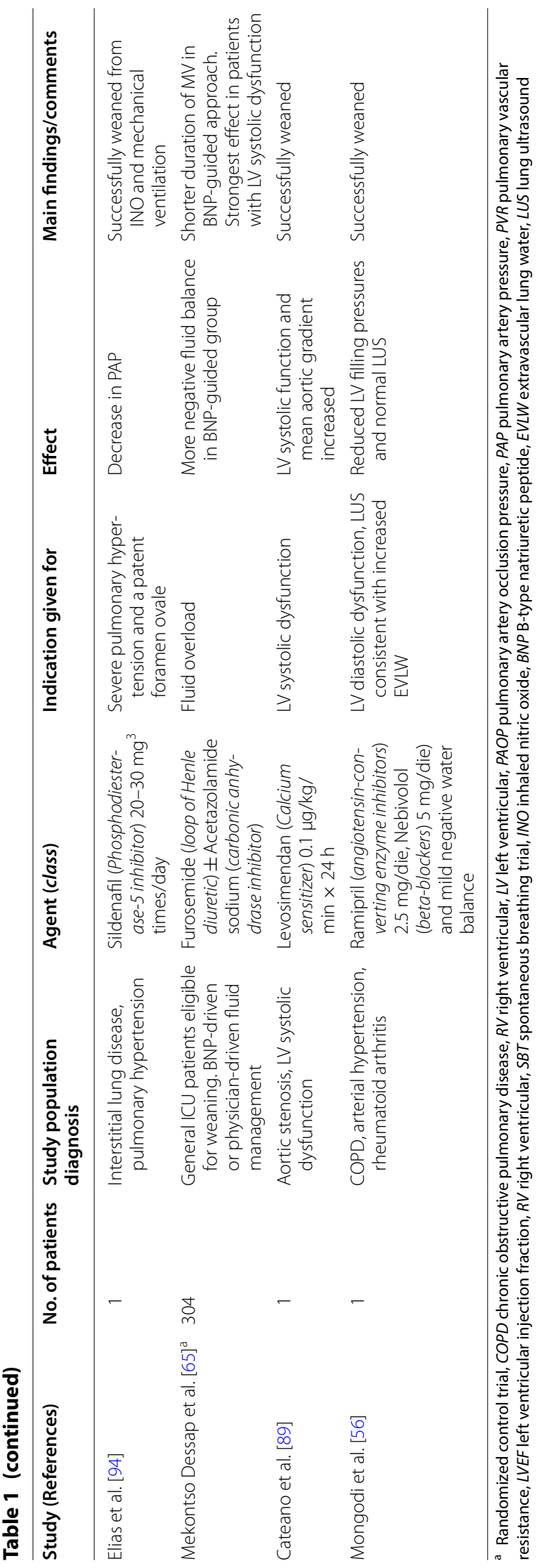


development of cardiogenic pulmonary edema during weaning of difficult-to-wean COPD patients with concomitant cardiovascular disease. These patients received intravenous furosemide $(80 \mathrm{mg} /$ day $)$ which resulted in a mean body weight reduction of $5 \mathrm{~kg}$ within a 10-day period due to fluid loss. As a result, a lower transmural PAOP was measured in eight patients who had undergone a repeated hemodynamic evaluation, and, thereafter, the majority of the patients $(9 / 15)$ were successfully weaned from mechanical ventilation.

Consequently, since correction of fluid balance is an absolutely modifiable variable, it is of great importance and deserves a routine attention by ICU clinicians. However, overtreatment with diuretics resulting in undesirable side effects including dehydration, hypovolemia and sometimes hypotension and renal dysfunction, is an imminent risk. Particularly, in patients with heart failure and preserved ejection fraction (i.e., LV diastolic dysfunction), aggressive diuresis may result in cardiac output reduction, since these patients are highly sensitive to volume changes and generally have a narrow window between volume overload, causing congestive symptoms and hypovolemia leading to circulatory shock [75]. As a result, recognition of the potential hazards and individualized management is considered to be mandatory in order to protect the patient from inappropriate diuretic dosage. In brief, assessment of the volume and preload status is necessary, as only weaning failure due to excessive preload should be treated with diuretics.

\section{Acetazolamide}

As a side effect, diuretics may cause metabolic alkalosis which may depress cardiac output and/or central respiratory drive contributing, thus, to weaning failure or delay, especially in COPD patients. Acetazolamide, a carbonic anhydrase inhibitor, has been used to reverse metabolic alkalosis when fluid and potassium replacements are insufficient to correct blood alkalinity. In the aforementioned study by Mekontso Dessap et al. [65], when metabolic alkalosis was present, acetazolamide was added $(250 \mathrm{mg}$ every $8 \mathrm{~h}$ if $\mathrm{pH}>7.45$ or $500 \mathrm{mg}$ every $8 \mathrm{~h}$ if $\mathrm{pH}>7.50)$ in the absence of contraindications. However, in a randomized controlled trial, among mechanically ventilated COPD patients, the use of acetazolamide did not result in a significant reduction in the duration of mechanical ventilation [76]. It is important to note that the pharmacological effect of acetazolamide lasts longer than expected from the plasma half-life of the drug (5-6 h), as it has been shown in patients with COPD and pure metabolic alkalosis [77]. Therefore, it should be given with caution.

(2) Control of hypertension
Systolic blood pressure of more than $180 \mathrm{mmHg}$ or pressure change greater than $20 \%$ during SBT is among the criteria of clinical intolerance and indicators of weaning failure [35]. The etiology of the increased blood pressure during a SBT is most likely multivariable in origin, mainly triggered by hypoxemia, hypercapnia and enhanced sympathetic activity [6,27]. Additionally, pain, anxiety and withdrawal syndromes, usually from opioid use, are also responsible. Therefore, any antihypertensive therapy should be given only after exclusion of these reversible factors.

Obviously, patients with chronic hypertension should be treated before any weaning attempt. There are a lot of treatment options including beta-blocking agents, calcium channel blockers, vasodilators and angiotensinconverting enzyme inhibitors; the latter providing recent evidence of their benefits in ICU patients with acute kidney injury [78]. These agents decrease arterial pressure via different modes of action, which may be appropriate or contraindicated in individual patients. Selecting the right drug after individualized evaluation is fundamental. As a general rule, pharmaceutical agents with rapid onset and short half-life/duration of action are preferable [79].

In almost all studies of weaning failure of cardiovascular origin, systolic blood pressure increased immediately after the start of an unsuccessful SBT $[6,15,18,19,44]$. As it has been shown by Jubran et al. this rise in systolic blood pressure during unsuccessful SBTs was associated with a lack of change in cardiac index, implying an increase in LV afterload [44]. Therefore, optimal therapy should include agents capable of decreasing high arterial blood pressure through reduction in the afterload, such as vasodilators.

In hyperadrenergic states, where tachycardia is typically present, selective beta1-blocking agents are good options for the control of hypertension. Clonidine, a central-acting a2-agonist, may also be a good alternative. It induces a decrease in the sympathetic tone with a significant reduction in blood pressure. It is most useful in patients with drug or alcohol withdrawal and also in those patients in whom a vasodilatory effect is best avoided, e.g., in the presence of intracranial hypertension.

\section{(3) Vasoactive cardiovascular agents}

\section{Catecholamines Dopamine}

Dopamine, at infusion rates of $2-15 \mu \mathrm{g} / \mathrm{kg} / \mathrm{min}$, stimulates $\beta 1$-receptors and increases myocardial contractility as well as splanchnic blood flow at the cost of tachycardia and increased risk of arrhythmias [80]. In an earlier study, Aubier and colleagues [81] investigated the effect of 
dopamine on diaphragmatic strength and blood flow in COPD patients mechanically ventilated because of acute on chronic respiratory failure. Following a dose of $10 \mu \mathrm{g} /$ $\mathrm{kg}$ during 30 min heart rate increased by $17 \%$ and cardiac output by $40 \%$ on average, accompanied by a marked increase in diaphragmatic blood flow and transdiaphragmatic pressure. Although the authors demonstrated these favorable effects of dopamine on diaphragmatic function, weaning outcome was not reported. Later, Ciarka A. et al. investigated the impact of low-dose dopamine on weaning from mechanical ventilation in COPD patients [82]. Dopamine did not attenuate ventilation and had no effect on arterial blood gases. Effects of dopamine infusion on cardiovascular system were not reported.

\section{Dobutamine}

Dobutamine, a catecholamine derivative with specificity for beta-1 adrenergic receptors, is usually reserved for patients with severe reduction in cardiac output leading to compromised vital organ perfusion [39]. Theoretically, optimizing LV function with a short-acting inotropic agent seems to be a reasonable approach to weaning failure due to LV systolic dysfunction. However, the potential adverse effects of dobutamine, including increased heart rate with concomitant increased myocardial oxygen demand, render it unlikely to be beneficial. Furthermore, the sympathetic nervous system activation expressed by catecholamine excess during failed SBTs, does not support exogenous catecholamine administration. Finally, dobutamine is not indicated for treatment of cardiac failure with preserved ejection fraction (i.e., diastolic heart failure) $[39,47]$, which is a common cause of weaning failure of cardiovascular origin.

Indeed, when dobutamine at a dosage of $7 \mu \mathrm{g} / \mathrm{kg} / \mathrm{min}$ was given in 10 difficult-to-wean COPD patients exhibiting weaning difficulties associated with increased PAOP during SBTs [83], the rate-pressure product which is a global index of myocardial workload and myocardial oxygen demand [84] was significantly increased. One could comment on the absence of a clear indication of dobutamine administration in those patients, since there was no evidence of impaired LV contractility, as shown by a LV ejection fraction within the normal range.

\section{Phosphodiesterase-3 inhibitors}

Phosphodiesterase- 3 inhibitors, such as milrinone, amrinone and enoximone, are another inotropic class of agents; they have attractive systemic and pulmonary vasodilatory properties potentially useful in right ventricular failure and pulmonary hypertension, but are often associated with hypotension and arrhythmias.

Enoximone has been evaluated in the treatment of LV dysfunction after cardiac surgery, in nine patients with one or more unsuccessful attempts of weaning due to LV dysfunction [20]. Enoximone was given at a dose of $10 \mu \mathrm{g} / \mathrm{kg} / \mathrm{min}$ for the first $30 \mathrm{~min}$ followed by $30 \mu \mathrm{g} /$ $\mathrm{kg} / \mathrm{min}$. During spontaneous ventilation, cardiac index increased by $34 \%$, but mean arterial, right atrial pressure and PAOP did not change. Despite an increase in venous admixture due to augmented cardiac index and inhibition of hypoxic vasoconstriction, no oxygen debt occurred because of increased oxygen delivery. Seven of nine patients were weaned successfully from mechanical ventilation. Similarly, in six coronary patients with pulmonary edema after discontinuing mechanical ventilation, the administration of enoximone prevented LV dysfunction in five of them and enabled successful weaning [21]. No other studies exist; therefore, there are insufficient data to support enoximone use in clinical scenarios of weaning failure.

\section{Calcium sensitizer (Levosimendan)}

Levosimendan is a novel calcium sensitizer and ATPsensitive potassium channel opener. Its mode of action is completely independent of the $\beta_{1}$-adrenergic pathway. In contrast to catecholamines, levosimendan enhances cardiac contractility without increasing myocardial oxygen demand and inducing negative impact on diastolic function [85]. In addition, levosimendan has a marked "decongestive" benefit; it reduces cardiac filling pressures and pulmonary vascular resistance through a vasodilator effect, decreasing, thus, RV afterload [86]. Therefore, it might be particularly beneficial for patients with concomitant pulmonary hypertension.

The clinical benefits of levosimendan in difficult-towean patients because of cardiovascular dysfunction have been highlighted in few reports [17, 83, 87-89]. Levosimendan was given in ventilator-dependent patients with impaired LV function, who had failed a SBT or extubation attempt, and were already under diuretic and vasodilator treatment. Following a 24-h infusion of levosimendan, weaning from mechanical ventilation was re-attempted. Levosimendan significantly improved LV ejection fraction and oxygenation variables and contributed to successful weaning in 7 out of 12 patients [17]. Also, the short-term hemodynamic effects of levosimendan, compared to dobutamine, were studied in 10 COPD patients experiencing weaning difficulties related to increased PAOP [83]. Levosimendan resulted in significantly greater inhibition of SBT-induced increase in PAOP and mean pulmonary artery pressure than dobutamine. Moreover, on mechanical ventilation, the rate-pressure product remained constant with levosimendan infusion, whereas it was significantly increased with dobutamine infusion. All included patients were ultimately extubated without the adjunct of any other cardiovascular 
drug. Lastly, use of levosimendan effectively contributed to successful weaning in difficult-to-wean patients with impaired LV function in a study available only in an abstract form [87] as well as in single patients with LV dysfunction of various etiologies $[88,89]$.

The therapeutic potential of levosimendan seems to be beyond its effects on LV performance [90]. As it has been shown experimentally in a canine model with compromised cardiac function, levosimendan improved the splanchnic mucosal oxygenation that was depressed by mechanical ventilation [91]. Furthermore, levosimendan improved the neuromechanical efficiency and contractile function of the human diaphragm in vivo (healthy subjects) as well as in vitro (muscle fibers from COPD patients' diaphragm), suggesting a therapeutic approach to improve respiratory muscle function [92]. A currently ongoing randomized clinical trial (ClinicalTrials. gov identifier NCT01721434) has planned to determine whether levosimendan improves weaning outcome from mechanical ventilation. However, preexisting cardiovascular disease is an excluding factor in this protocol.

Taken together, levosimendan might exert a double beneficial effect during the critical period of weaning from mechanical ventilation in difficult-to-wean patients with impaired cardiovascular function. However, it should be noted that the addition of levosimendan to the standard treatment in adults with sepsis was associated with a lower likelihood of successful weaning from mechanical ventilation and a higher risk of supraventricular tachyarrhythmias [93]. Therefore, its efficacy and safety regarding this indication are still uncertain.

\section{Vasodilators \\ Nitroglycerin}

By systemic venous and arterial vasodilatory properties, nitroglycerin results in reduction in venous return and LV afterload. In addition, by coronary vasodilation, it is beneficial in those patients with a concomitant coronary syndrome, either confirmed as such or highly suspected to develop. Nitroglycerine is a short-acting vasodilator having a rapid onset (2-5 $\mathrm{min})$ and short duration of action (5-10 min). The hemodynamic and clinical effects of nitroglycerin were studied in COPD patients who repeatedly failed to wean from mechanical ventilation exhibiting systemic arterial hypertension [18]. While the mean systemic arterial pressure, rate-pressure product, mean pulmonary arterial pressure, and PAOP increased in failing trials, these variables remained stable under high dosing of nitroglycerin (Fig. 4). These favorable hemodynamic effects were associated with a successful SBT and extubation in $92 \%$ and $88 \%$ of patients, respectively. Interestingly, nitroglycerin treatment resulted in a lesser extent of arterial $\mathrm{PO}_{2}$ decrease and venous admixture increase compared to control, possibly indicating a reduction in weaning-induced acute pulmonary congestion. Other studies are lacking, thus, this treatment in weaning failure of cardiovascular origin remains to be further investigated.

\section{Phosphodiesterase- 5 inhibitors (Sildenafil)}

Phosphodiesterase-5 inhibitors have been used in selected mechanically ventilated patients with pulmonary hypertension and difficult weaning in order to take advantage of their short-term acute vasodilatory effects on pulmonary circulation. The first report included three COPD patients with repeated SBT failures [19]. These patients received $50 \mathrm{mg}$ of sildenafil through the nasogastric tube under respiratory and hemodynamic monitoring with a pulmonary artery catheter. After sildenafil treatment, pulmonary artery pressure and PAOP decreased. The respiratory frequency to tidal volume index and the difference in arterial minus end-tidal carbon dioxide pressure decreased as well, indicating a beneficial effect of sildenafil on the pattern of breathing and reduction in the physiological dead space, respectively. The patients were successfully extubated. Similarly, sildenafil $20-30 \mathrm{mg}$ three times daily enabled weaning from mechanical ventilation and inhaled nitric oxide in a patient with acute respiratory failure due to severe pulmonary hypertension and a right-to-left shunt through a patent foramen ovale [94]. Finally, in a mechanically ventilated patient with right ventricular dysfunction related to secondary pulmonary hypertension, sildenafil $25 \mathrm{mg}$ every $8 \mathrm{~h}$ successfully substituted inhaled nitric oxide, inducing a sustained reduction in pulmonary pressures without any systemic adverse effect, in terms of systemic arterial pressure, cardiac index and mixed venous oxygen saturation, thus, facilitating the discontinuation of respiratory and cardiovascular organ support [95]. Phosphodiesterase- 5 inhibition has also been reported to reverse bronchoconstriction [96] and to improve the pulmonary function [97]. However, it should be stressed that, sildenafil, despite its reported favorable results in pulmonary hypertension cases, cannot be currently recommended due to the limited evidence.

\section{(4) Beta-blockers}

Beta-blockers have occasionally been used to facilitate weaning in specific conditions. In one report of two elderly patients with weaning-induced pulmonary edema refractory to treatment with diuretics, vasodilators and inotropes, TTE data confirmed the diagnosis of hypertrophic obstructive cardiomyopathy and they were successfully managed with beta-blockers (atenolol $200 \mathrm{mg} /$ day) and calcium channel blockers (diltiazem 

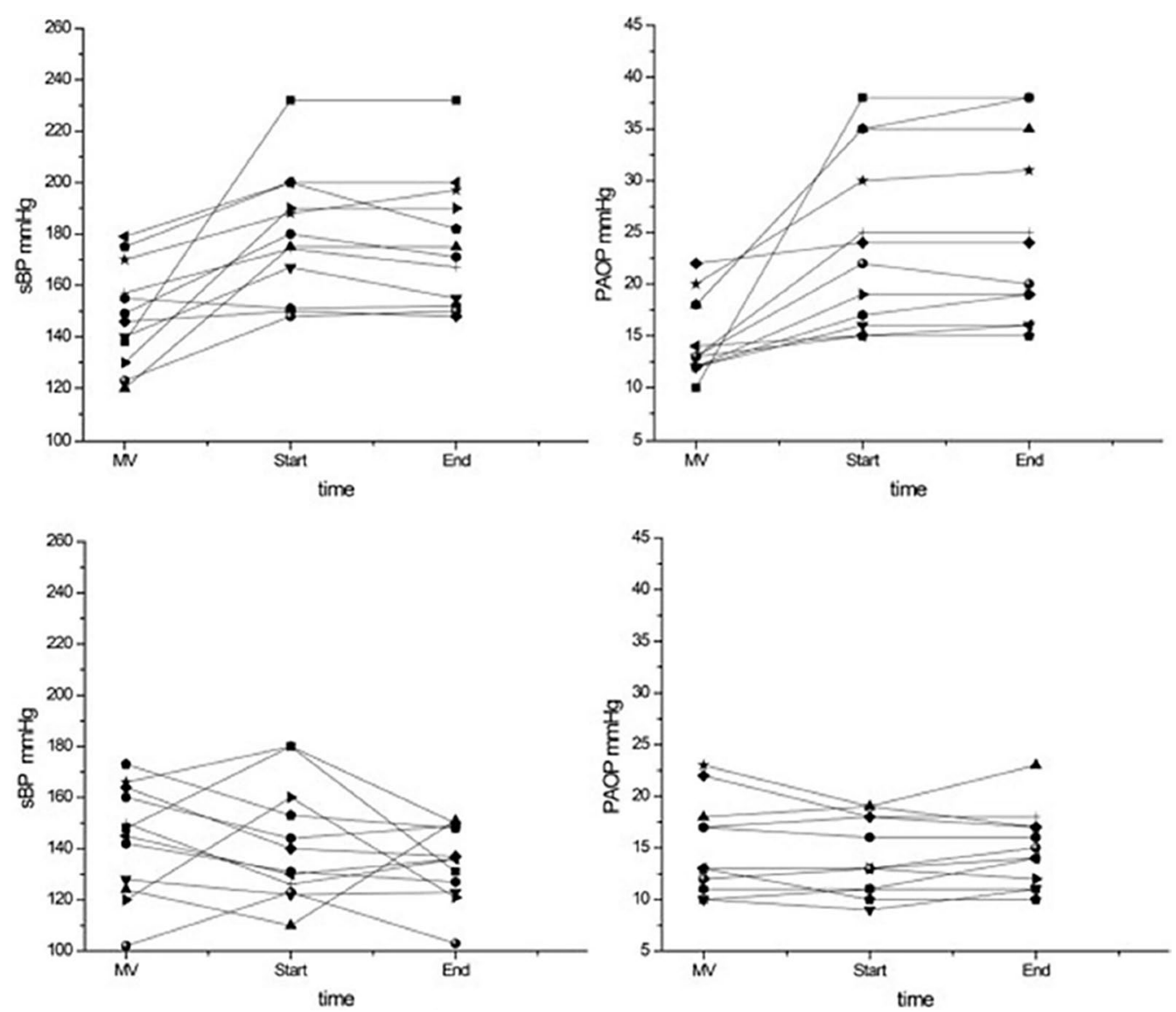

Fig. 4 Individual values of systolic blood pressure (sBP) (left) and pulmonary artery occlusion pressure (PAOP) (right) obtained on mechanical ventilation (MV) and at the 10th minute (Start) and the last minute (End) of a spontaneous breathing trial without (upper panel) and with nitroglycerin treatment (lower panel) (adapted from [18])

$300 \mathrm{mg} /$ day) [98]. Similarly, beta-blockers in combination with angiotensin-converting enzyme inhibitors and mild negative water balance successfully treated cardiogenic pulmonary edema associated with LV diastolic dysfunction, unmasked during SBT [56], as well as in a trauma patient with documented coronary artery disease [99]. These reports highlight the need for an accurate diagnosis in order to individualize the management of weaning failure of cardiovascular origin.

\section{Non-pharmacological strategies}

Beyond pharmacological treatments, other measures such as ventilatory strategies and/or cardiac interventional procedures, when indicated, have been used to improve the outcome of the weaning due to cardiovascular dysfunction.

(1) Ventilatory strategies/SBT technique
The choice of the appropriate SBT technique is controversial. Cabello et al. compared SBT on T-piece with that on PSV, with and without PEEP, in patients who had failed a previous T-piece trial and had a pulmonary artery catheter in place [9]. During SBTs, patients on T-piece exhibited more negative intrathoracic pressures as well as greater increases in systemic blood pressure and PAOP, indicating that T-piece strategy might be more challenging for the heart compared to PSV with PEEP. Noteworthy, $50 \%$ of these patients had COPD and $80 \%$ of those who exhibited a PAOP above $18 \mathrm{mmHg}$ during the failed T-piece trial had concomitant cardiovascular disease. Most patients succeeded the PSV trial, although all patients failed the T-piece one. A recent meta-analysis confirmed that PSV significantly reduces the work of breathing compared with T-piece [100]. Therefore, for patients with impaired cardiovascular function, gradual withdrawing of mechanical ventilation by PSV seems less stressful for the cardiovascular system than the abrupt stop by T-piece trial. 
On the other hand, as it has been emphasized by Tobin [101], even a low level of PEEP during SBT through PSV can decrease the work of breathing by as much as $40 \%$ in ventilated patients and also can produce a substantial increase in cardiac output in patients with LV failure. Therefore, by applying "minimal ventilator settings," i.e., PSV of $5 \mathrm{~cm} \mathrm{H}_{2} \mathrm{O}$ with PEEP or continuous positive airway pressure (CPAP) of $5 \mathrm{~cm} \mathrm{H}_{2} \mathrm{O}$, causes physicians to overestimate the patient's capacity to handle an increase in cardiorespiratory load following extubation, thus, resulting in extubation failure. Therefore, using a trial of unassisted breathing (i.e., T-piece trial) seems reasonable, especially in patients who might experience cardiorespiratory difficulties after extubation (i.e., those with impaired cardiovascular function), because this strategy may unmask the need for further optimization of cardiorespiratory function.

(2) Use of noninvasive ventilation in the post-extubation period as a weaning adjunct

Noninvasive ventilation (NIV) has been shown to be useful as adjunctive therapy in the treatment of respiratory failure in acute heart failure syndromes [102] such as acute cardiogenic pulmonary edema, including cases due to LV diastolic dysfunction [103]. Also, NIV has an important role in the treatment or prevention of post-extubation respiratory failure in selected high-risk patient groups [104-106]. Recent guidelines issued by the American Thoracic Society and the American College of Chest Physicians recommend, for patients at high risk of extubation failure (elderly, COPD, congestive heart failure, or hypercapnia during the SBT) who have been receiving mechanical ventilation for $>24 \mathrm{~h}$ and passed a SBT, extubation to preventive NIV as superior to nonpreventive NIV regarding extubation success, ICU, and both short- and long-term mortality [107]. Physicians who choose to use NIV should apply such treatment immediately after extubation to realize the outcome benefits.

Finally, high-flow nasal cannula oxygen therapy, an evidence-based modality for treatment of hypoxemic respiratory failure, was found noninferior to NIV in postextubation settings for patients at high risk of respiratory failure [108]. However, there is no data regarding its use after extubation in patients at high risk of weaninginduced pulmonary edema.

\section{(3) Cardiac interventional procedures}

Medical treatment of weaning failure due to cardiovascular dysfunction may be ineffective in certain circumstances, such as in critically ill patients with myocardial ischemia or/and in the setting of valvulopathy.
In such cases, further therapeutic approaches should be considered.

Persistent weaning failure from mechanical ventilation because of pulmonary edema due to myocardial ischemia has been successfully treated with coronary angioplasty in two patients with known preexisting myocardial ischemia $[109,110]$. The intervention was followed by improvement in coronary perfusion that allowed successful extubation. Similarly, in another case in which weaning was impossible, percutaneous balloon mitral commissurotomy for severe mitral stenosis was successfully performed, resulting in removal of the ventilator $24 \mathrm{~h}$ later [30]. In another patient with COPD and extensive myocardial ischemia, previously unknown, detected after repeated failing SBTs, a coronary artery bypass graft surgery was performed because optimal pharmaceutical treatment proved ineffective and coronary angioplasty was not technically feasible due to extensive stenotic lesions [111]. The patient was successfully weaned the third postoperative day. Finally, cardiac resynchronization therapy may assist weaning from circulatory and respiratory support in critically ill patients with LV systolic dysfunction [112].

\section{Conclusion}

Cardiovascular dysfunction is an important cause or contributor to weaning failure. Early identification of high-risk patients for weaning failure of cardiovascular origin and accurate diagnosis is crucial, as targeted treatment according to the underlying mechanism might help the heart to tolerate more effectively the burden of weaning process.

Specific evidence-based recommendations for treating confirmed weaning failure of cardiovascular origin cannot be applied, at least at the moment, due to the lack of data derived from clinical trials. However, based on both pathophysiology and data derived from small-scale studies, causal pharmacological approach is being applied in real life daily practice, such as prompt diuresis in excessive preload, nitrates in excessive afterload and/or myocardial ischemia or other rational treatment in specific indications. Until appropriate evidence emerges, tailoring cardiovascular treatment and monitoring the individual responses to therapy should be carefully performed by ICU clinicians, reminding that much further research is required.

\footnotetext{
Abbreviations

ICU: intensive care unit; PSV: pressure support ventilation; COPD: chronic obstructive pulmonary disease; $\mathrm{SBT}$ : spontaneous breathing trial; $\mathrm{S}_{\mathrm{O}} \mathrm{O}_{2}$ : mixed venous oxygen saturation; $\mathrm{SCVO}_{2}$ : central venous oxygen saturation; TTE: transthoracic echocardiography; TDI: tissue Doppler imaging; TP: transpulmonary; PA: pulmonary artery; PAOP: pulmonary artery occlusion pressure; LV: left ventricular; BNP: B-type natriuretic peptide; EVLW: extravascular lung water; PLR: passive leg raising; ACE: angiotensin-converting enzyme; CPAP: continuous positive airway pressure; NIV: noninvasive ventilation.
} 


\section{Authors' contributions}

All authors contributed to writing the manuscript and have reviewed and approved the final version. All authors read and approved the final manuscript.

\section{Author details}

${ }^{1}$ First Department of Critical Care, Medical School, National and Kapodistrian University of Athens, "Evangelismos" Hospital, Ipsilantou 45-47, 10676 Athens, Greece. ${ }^{2}$ Respiratory Failure Unit, Medical School, "G. Papanikolaou" Hospital, Aristotle University, Thessaloníki, Greece. ${ }^{3}$ Department of Cardiology, "Evangelismos" Hospital, Athens, Greece.

\section{Competing interests}

The authors have no competing of interest nor any financial interest in any product mentioned in this paper.

\section{Availability of data and materials \\ NA.}

\section{Consent for publication}

NA

\section{Ethics approval and consent to participate}

NA.

\section{Publisher's Note}

Springer Nature remains neutral with regard to jurisdictional claims in published maps and institutional affiliations.

Received: 24 September 2018 Accepted: 2 January 2019

Published online: 09 January 2019

\section{References}

1. Perren A, Brochard L. Managing the apparent and hidden difficulties of weaning from mechanical ventilation. Intensive Care Med. 2013;39:1885-95.

2. Doorduin J, van de Hoeven JG, Heunks LMA. The differential diagnosis for failure to wean from mechanical ventilation. Curr Opin Anesthesiol. 2016;29:150-7.

3. Jubran A, Tobin MJ. Pathophysiologic basis of acute respiratory distress in patients who fail a trial of weaning from mechanical ventilation. Am J Respir Crit Care Med. 1997;155:906-15.

4. Vassilakopoulos T, Zakynthinos S, Roussos C. The tension-time index and the frequency/tidal volume ratio are the major pathophysiologic determinants of weaning failure and success. Am J Respir Crit Care Med. 1998;158:378-85.

5. McConville JF, Kress JP. Weaning patients from the ventilator. N Engl J Med. 2012;367:2233-9.

6. Lemaire F, Teboul JL, Cinotti L, Giotto G, Abrouk F, Steg G, et al. Acute left ventricular dysfunction during unsuccessful weaning from mechanical ventilation. Anesthesiology. 1988;69:171-9.

7. Jubran A. Weaning-induced cardiac failure. In: Mancebo J, Net A, Brochard $L$, editors. Mechanical ventilation and weaning. Update in intensive care and emergency medicine, vol. 36. Berlin: Springer; 2002. p. 184-92.

8. Epstein SK. Etiology of extubation failure and the predictive value of the rapid shallow breathing index. Am J Resp Crit Care Med. 1995:152:545-9.

9. Cabello B, Thille AW, Roche-Campo F, Brochard L, Gómez FJ, Mancebo J. Physiological comparison of three spontaneous breathing trials in difficult-to-wean patients. Intensive Care Med. 2010;36:1171-9.

10. Dres M, Teboul JL, Anguel N, Guerin L, Richard C, Monnet X. Extravascular lung water, B-type natriuretic peptide and blood volume contraction enable diagnosis of weaning-induced pulmonary edema. Crit Care Med. 2014:42:1882-9.

11. Caille V, Amiel JB, Charron C, Belliard G, Vieillard-Baron A, Vignon P. Echocardiography: a help in the weaning process. Crit Care. 2010:14:R120.
12. Liu J, Shen F, Teboul JL, Anguel N, Beurton A, Bezaz N, et al. Cardiac dysfunction induced by weaning from mechanical ventilation: incidence, risk factors, and effects of fluid removal. Crit Care. 2016;20:369.

13. Roche-Campo F, Bedet A, Vivier E, Brochard L, Mekontso Dessap A. Cardiac function during weaning failure: the role of diastolic dysfunction. Ann Intensive Care. 2018;8:2.

14. Teboul JL. Weaning-induced cardiac dysfunction: where are we today? Intensive Care Med. 2014;40:1069-79.

15. Grasso S, Leone A, De Michele M, Anaclerio R, Cafarelli A, Ancona $\mathrm{G}$, et al. Use of $\mathrm{N}$ terminal pro-brain natriuretic peptide to detect acute cardiac dysfunction during weaning failure in difficult-to-wean patients with chronic obstructive pulmonary disease. Crit Care Med. 2007:35:96-105

16. Dres $M$, Teboul JL, Monnet X. Weaning the cardiac patient from mechanical ventilation. Current opinion in critical care. 2014;20:493-8.

17. Sterba M, Banerjee A, Mudaliar Y. Prospective observational study of levosimendan and weaning of difficult- to- wean ventilator dependent intensive care patients. Crit Care Resusc. 2008;10:182-6.

18. Routsi C, Stanopoulos I, Zakynthinos E, Politis P, Papas V, Zervakis D, et al. Nitroglycerin can facilitate weaning of difficult-to-wean chronic obstructive pulmonary disease patients: a prospective interventional nonrandomized study. Crit Care. 2010;14:R204.

19. Stanopoulos I, Manolakoglou N, Pitsiou G, Trigonis I, Tsiata EA, Boutou AK, et al. Sildenafil may facilitate weaning in mechanically ventilated COPD patients: a report of three cases. Anaesth Intensive Care 2007;35:610-3.

20. Paulus S, Lehot JJ, Bastien O, Piriou V, George M, Estanove S. Enoximone and acute left ventricular failure during weaning from mechanical ventilation after cardiac surgery. Crit Care Med. 1994;22:74-80.

21. Valtier B, Teboul JL, Lemaire F. Left ventricular dysfunction while weaning from mechanical ventilation. Contribution of enoximone. Arch Mal Coeur Vaiss. 1990;83:83-6.

22. Luce JM. The cardiovascular effects of mechanical ventilation and positive expiratory pressure. JAMA. 1984;252:807-11.

23. Pinsky MR. Cardiovascular effects of ventilator support and withdrawal. Anesh Analg. 1994;79:567-76.

24. Buda AJ, Pinsky MR, Ingels NB, Daughters GT, Stinson EB, Alderman EL. Effect of intrathoracic pressure on left ventricular performance. N Engl J Med. 1979;301:453-9.

25. Scharf SM, Brown R, Tow DE, Parisi AF. Cardiac effects of increased lung volume and decreased pleural pressure in man. J Appl Physiol. 1979:47:257-62.

26. Scharf SM, Brown R, Saunders N, Green LH. Effects of normal and loaded spontaneous inspiration on cardiovascular function. J Appl Physiol. 1979;47:582-90.

27. Oh TE, Bhatt S, Lin ES, Hutchinson RC, Low JM. Plasma catecholamines and oxygen consumption during weaning from mechanical ventilation. Intensive Care Med. 1991;17:199-203.

28. Scharf SM, Bianco JA, Tow DE, et al. The effects of large negative intrathoracic pressure on left ventricular function in patients with coronary artery disease. Circulation. 1981;63:871-5.

29. Rasanen J, Nikki P, Heikkila J. Acure myocardial infarction complicated by respiratory failure. Chest. 1984;85:21-8.

30. Demoule A, Lefort $Y$, Lopes ME, et al. Successful weaning from mechanical ventilation after coronary angioplastry. Br J Anesth. 2004;93:295-7.

31. de Meirelles Almeida CA, Nedel WL, Morais VD, Boniatti MM, de Almeida-Filho OC. Diastolic dysfunction as a predictor of weaning failure: a systematic review and meta-analysis. J Crit Care. 2016;34:135-41.

32. Thille AW, Boissier F, Ben Ghezala H, Razazi K, Mekontso-Dessap A, Brun-Buisson C. Risk factors for and prediction by caregivers of extubation failure in ICU patients: a prospective study. Crit Care Med. 2015:43:613-20

33. Papanikolaou J, Makris D, Saranteas T, Karakitsos D, Zintzaras E, Karabinis $A$, et al. New insights into weaning from mechanical ventilation: left ventricular diastolic dysfunction is a key player. Intensive Care Med. 2011:37:1976-85.

34. Konomi I, Tasoulis A, Kaltsi I, Karatzanos E, Vasileiadis I, Temperikidis P, Nanas S, Routsi Cl. Left ventricular diastolic dysfunction-an independent risk factor for weaning failure from mechanical ventilation. Anaesth Intensive Care. 2016:44:466-73. 
35. Boles JM, Bion J, Connors A, Herridge M, Marsh B, Melot C, et al. Weaning from mechanical ventilation. Eur Respir J. 2007;29:1033-56.

36. Rasmussen $\mathrm{T}$, Kober $\mathrm{L}$, Pedersen $\mathrm{JH}$, et al. Relationship between chronic obstructive pulmonary disease and subclinical coronary artery disease in long-term smokers. Eur Heart J Cardiovascul Imaging. 2013;14:1159-66.

37. MacDonald MI, Shafuddin E, King PT, Chang CL, Bardin PG, Hancox RJ. Cardiac dysfunction during exacerbations of chronic obstructive pulmonary disease. Lancet Respir Med. 2016;4:138-48.

38. Matamis D, Tsagourias M, Papathanasiou A, Sineffaki H, Lepida D, Galiatsou $\mathrm{E}$, et al. Targeting occult heart failure in intensive care unit patients with acute chronic obstructive pulmonary disease exacerbation: effect on outcome and quality of life. J Crit Care. 2014;315:e7-14.

39. McMurray JJ, Adamopoulos S, Anker SD, et al. ESC guidelines for the diagnosis and treatment of acute and chronic heart failure 2012: the task force for the diagnosis and treatment of acute and chronic heart failure 2012 of the European Society of Cardiology. Developed in collaboration with the Heart Failure Association (HFA) of the ESC. Eur J Heart Fail. 2012;14:803-69.

40. Thille AW, Harrois A, Schortgen F, Brun-Buisson C, Brochard L. Outcomes of extubation failure in medical intensive care unit patients. Crit Care Med. 2011;39:2612-8.

41. Dres M, Teboul JL, Anguel N, Guerin L, Richard C, Monnet X. Passive leg raising performed before a spontaneous breathing trial predicts weaning-induced cardiac dysfunction. Intensive Care Med. 2015;41:487-94.

42. Zapata L, Vera P, Roglan A, Gich I, Ordonez-Llanos J, Betbese AJ. B-type natriuretic peptides for prediction and diagnosis of weaning failure from cardiac origin. Intensive Care Med. 2011;37:477-85.

43. Mauri T, Yoshida T, Bellani G, Goligher EC, Carteaux G, Rittayamai N, et al. Esophageal and transpulmonary pressure in the clinical setting: meaning, usefulness and perspectives. Intensive Care Med. 2016;42:1360-73.

44. Jubran A, Mathru M, Dries D, Tobin MJ. Continuous recordings of mixed venous oxygen saturation during weaning from mechanical ventilation and the ramifications thereof. Am J Respir Crit Care Med. 1998;158:1763-9.

45. Zakynthinos S, Routsi C, Vassilakopoulos T, Kaltsas P, Zakynthinos E, Kazi D, et al. Differential cardiovascular responses during weaning failure: effects on tissue oxygenation and lactate. Intensive Care Med. 2005:31:1634-42.

46. Harvey S, Harrison DA, Singer M, Ashcroft J, Jones CM, Elbourne D, et al. Assessment of the clinical effectiveness of pulmonary artery catheters in management of patients in intensive care (PAC-man): a randomized controlled trial. Lancet. 2005:366:472-7.

47. Teboul JL, Monnet X, Richard C. Weaning failure of cardiac origin: recent advances. Crit Care. 2010;14:211.

48. Vignon P. Cardiovascular failure and weaning. Ann Transl Med. 2018;6:354-63.

49. Nagueh S, Smiseth O, Appleton C, Byrd B, Dokainish H, Edvardsen T, et al. Recommendations for the evaluation of left ventricular diastolic function by echocardiography: an update from the American Society of Echocardiography and the European Association of Cardiovascular Imaging. J Am Soc Echocardiogr. 2016;29:277-314.

50. Lamia B, Maizel J, Ochagavia A, Chemla D, Osman D, Richard C, et al. Echocardiographic diagnosis of pulmonary artery occlusion pressure elevation during weaning from mechanical ventilation. Crit Care Med. 2009:37:1696-701.

51. Moschietto S, Doyen D, Grech L, Dellamonica J, Hyvernat H, Bernardin G. Transthoracic echocardiography with Doppler tissue imaging predicts weaning failure from mechanical ventilation: evolution of the left ventricle relaxation rate during a spontaneous breathing trial is the key factor in weaning outcome. Crit Care. 2012;16:R81.

52. Gerbaud E, Erickson M, Grenouillet-Delacre M, Beauvieux MC, Coste P, Durrieu-Jais C, et al. Echocardiographic evaluation and N-terminal pro-brain natriuretic peptide measurement of patients hospitalized for heart failure during weaning from mechanical ventilation. Minerva Anestesiol. 2012;78:415-25.

53. Ait-Oufella H, Tharaux PL, Baudel JL, Vandermeersch S, Meyer P, Tonnellier $M$, et al. Variation in natriuretic peptides and mitral flow indexes during successful ventilatory weaning: a preliminary study. Intensive Care Med. 2007;33:1183-6.

54. Ruiz-Bailén M, Cobo-Molinos J, Castillo-Rivera A, Cárdenas-Cruz A, Martínez-Amat A, Sevilla-Martínez M, et al. Stress echocardiography in patients who experienced mechanical ventilation weaning failure. J Crit Care. 2017;39:66-71.

55. Copetti R, Soldati G, Copetti P. Chest sonography: a useful tool to differentiate acute cardiogenic pulmonary edema from acute respiratory distress syndrome. Cardiovasc Ultrasound. 2008:6:16.

56. Mongodi S, Via G, Bouhemad B, Storti E, Mojoli F, Braschi A. Usefulness of combined bedside lung ultrasound and echocardiography to assess weaning failure from mechanical ventilation: a suggestive case. Crit Care Med. 2013;41:e182-5.

57. Via G, Storti E, Gulati G, Neri L, Mojoli F, Braschi A. Lung ultrasound in the ICU: from diagnostic instrument to respiratory monitoring tool. Minerva Anestesiol. 2012;78:1282-96.

58. Mayo P, Volpicelli G, Lerolle N, Schreiber A, Doelken P, Vieillard-Baron A. Ultrasonography evaluation during the weaning process: the heart, the diaphragm, the pleura and the lung. Intensive Care Med. 2016:42:1107-17.

59. Hurford WE, Favorito F. Association of myocardial ischemia with failure to wean from mechanical ventilation. Crit Care Med. 1995;23:1475-80.

60. Abalos A, Leibowitz AB, Distefano D, Halpern N, Iberti TJ. Myocardial ischemia during the weaning period. Am J Crit Care. 1992;1:32-6.

61. Chatila W, Ani S, Guaglianone D, Jacob B, Amoateng-Adjepong Y, Manthous CA. Cardiac ischemia during weaning from mechanical ventilation. Chest. 1996;109:1577-83.

62. Hurford WE, Lynch KE, Strauss HW, Lovenstein E, Zapol WM. Myocardial perfusion as assessed by thallium-201 scintigraphy during the discontinuation of mechanical ventilation in ventilator-dependent patients. Aneshesiology. 1991;74:1007-16.

63. Mekontso-Dessap A, de Prost N, Girou E, Braconnier F, Lemaire F, BrunBuisson C, et al. B-type natriuretic peptide and weaning from mechanical ventilation. Intensive Care Med. 2006;32:1529-36.

64. Chien JY, Lin MS, Huang YC, Chien YF, Yu CJ, Yang PC. Changes in B-type natriuretic peptide improve weaning outcome predicted by spontaneous breathing trial. Crit Care Med. 2008;36:1421-6.

65. Mekontso Dessap A, Roche-Campo F, Kouatchet A, et al. Natriuretic peptide-driven fluid management during ventilator weaning: a randomized controlled trial. Am J Respir Crit Care Med. 2012;186:1256-63.

66. Lubien E, DeMaria A, Krishnaswamy P, Clopton P, Koon J, Kazanegra $\mathrm{R}$, et al. Utility of B-natriuretic peptide in detecting diastolic dysfunction: comparison with Doppler velocity recordings. Circulation. 2002;105:595-601.

67. McCullough PA, Omland T, Maisel AS. B-type natriuretic peptides: a diagnostic breakthrough for clinicians. Rev Cardiovasc Med. 2003:4:72-80

68. Anguel N, Monnet X, Osman D, Castelain V, Richard C, Teboul JL. Increase in plasma protein concentration for diagnosing weaninginduced pulmonary oedema. Intensive Care Med. 2008;34:1231-8.

69. Jozwiak M, Teboul JL, Monnet X. Extravascular lung water in critical care: recent advances and clinical applications. Annals Intensive Care. 2015;5:38.

70. Monnet $X$, Teboul JL. Passive leg raising. Intensive Care Med. 2008;34:659-63.

71. Goligher EC, Ferguson ND, Brochard LJ. Clinical challenges in mechanical ventilation. Lancet. 2016;387:1856-66.

72. Frutos-Vivar F, Ferguson ND, Esteban A, Epstein SK, Arabi Y, Apezteguia $C$, et al. Risk factors for extubation failure in patients following a successful spontaneous breathing trial. Chest. 2006;130:164-71.

73. Upadya A, Tilluckdharry L, Muralidharan V, Amoateng-Adjepong Y, Manthous CA. Fluid balance and weaning outcomes. Intensive Care Med. 2005;31:1643-7.

74. Maeda K, Takayoshi T, Wada A, Hisanaga T, Kinoshita M. Plasma brain natriuretic peptide as a biochemical marker of high left ventricular end-diastolic pressure in patients with symptomatic left ventricular dysfunction. Am Heart J. 1998;135:825-32.

75. Howard PA. Treating heart failure with preserved ejection fraction: a challenge for clinicians. Hosp Pharm. 2015;50:454-9.

76. Faisy C, Meziani F, Planquette B, Clavel M, Gacouin A, Bornstain C, et al. Effect of acetazolamide vs placebo on duration of invasive mechanical ventilation among patients with chronic obstructive pulmonary disease: a randomized clinical trial. JAMA. 2016:315:480-8.

77. Mazur JE, Devlin JW, Peters MJ, Jankowski MA, lannuzzi MC, Zarowitz BJ. Single versus multiple doses of acetazolamide for metabolic alkalosis in 
critically ill medical patients: a randomized, double-blind trial. Crit Care Med. 1999;27:1257-61.

78. Alpern RJ, Peixoto AJ. Use of renin angiotensin system blockers after acute kidney injury: balancing tradeoffs. JAMA. 2018;178:1690-2.

79. Salgado DR, Silva E, Vincent JL. Control of hypertension in the critically ill: a pathophysiological approach. Annals Intensive Care. 2013;3:17.

80. Annane D, Quanes-Besbes L, De Backer D, Du B, Gordon AC, et al. A globar perspective on vasoactive agents in shock. Annals Intensive Care. 2018;44:833-46.

81. Aubier M, Murciano D, Menu Y, Boczkowski J, Mal H, Pariente R. Dopamine effects on diaphragmatic strength during acute respiratory failure in chronic obstructive pulmonary disease. Ann Intern Med. 1989:110:17-23.

82. Ciarka A, Rimacchi R, Vincent JL, Velez-Roa S, Dumonceaux M, Leeman $M$, van de Borne P. Effects of low-dose dopamine on ventilation in patients with chronic obstructive pulmonary disease. Eur J Clin Invest. 2004;34:508-12.

83. Quanes-Besbes L, Quanes I, Dachraoui F, Dimassi S, Mebazaa A, Abroug F. Weaning difficult -to-wean chronic obstructive pulmonary disease patients: a pilot study comparing initial hemodynamic effects of levosimendan and dobutamine. J Crit Care. 2011;26:15-21.

84. Gobel Fl, Norstrom LA, Nelson RR, Jorgensen CR, Wang Y. The rate pressure product as an index of myocardial oxygen consumption during exercise in patients with angina pectoris. Circulation. 1978;57:549-56.

85. Toller WG, Stranz C. Levosimendan, a new inotropic and vasodilator agent. Anesthesiology. 2006;104:556-69.

86. Kerbaul F, Rondelet B, Demester J-P, et al. Effects of levosimendan versus dobutamine on pressure load-induced right ventricular failure. Crit Care Med. 2006;34:2814-9.

87. Kaltsi I, Gratsiou C, Nanas S, Routsi C. Effects of Levosimendan on weaning from mechanical ventilation of patients with left ventricular dysfunction. Critical Care. 2018;22(Suppl 1):82.

88. Meaudre E, Jego C, Goutorbe P, Bordes J, Asencio Y, Montcriol A, et al. Weaning failure from mechanical ventilation due to dilated cardiomyopathy: successful use of levosimendan. Acta Anaesthesiol Scand. 2009:53:416-7.

89. Caetano F, Mota P, Barra S, Almeida I, Botelho A, Trigo J, et al. Use of levosimendan in critically ill patients with severe aortic stenosis and left ventricular dysfunction. Eur Heart J Acute Cardiovasc Care. 2012;1:281-4

90. Farmakis D, Alvarez J, Gal TB, Brito D, Fedele F, Fonseca C, et al. Levosimendan beyond inotropy and acute heart failure: evidence of pleiotropic effects on the heart and other organs: An expert panel position paper. Intern J Cardiol. 2016;222:303-12.

91. Fournell A, Scheeren TW, Picker O, Schwarte LA. Pharmacologic interventions to improve splanchnic oxygenation during ventilation with positive end-expiratory pressure. Adv Exp Med Biol. 2012;737:235-8.

92. Doorduin J, Sinderby CA, Beck J, et al. The calcium sensitizer levosimendan improves human diaphragm function. Am J Respir Crit Care Med. 2012;185:90-5

93. Gordon AC, Perkins GD, Singer M, McAuley DF, Orme RM, Santhakumaran $\mathrm{S}$, et al. Levosimendan for the prevention of acute organ dysfunction in sepsis. N Engl J Med. 2016;375:1638-48.

94. Elias S, Sviri S, Orenbuch-Harroch E, Fellig Y, Ben-Yehuda A, Fridlender ZG, et al. Sildenafil to facilitate weaning from inhaled nitric oxide and mechanical ventilation in a patient with severe secondary pulmonary hypertension and a patent foramen ovale. Respir Care. 2011;56:1611-3.

95. Ng J, Finney J, Shulman R, Bellingan GJ, Singer M, Glynne PE, et al. Treatment of pulmonary hypertension in a general adult intensive care unit: a role for oral sildenafil? Brit J Anaesh. 2005;94:774-7.

96. Trophy TJ. Phosphodiesterase isozymes: molecular targets for novel antiasthma agents. Am J Respir Crit Care Med. 1998;157:351-70.

97. Charan NB. Does sildenafil also improve breathing? Chest. 2001:120:305-6.

98. Adamopoulos C, Tsagourias M, Arvaniti K, Veroniki F, Matamis D. Weaning failure from mechanical ventilation due to hypertrophic obstructive cardiomyopathy. Intensive Care Med. 2005;31:734-7.
99. Duane DT, Redwood SR, Grounds RM. Esmolol aids extubation in intensive care patient with ischaemic pulmonary oedema. Anaesthesia. 1996:51:474-7.

100. Sklar MC, Burns K, Rittayamai N, Lanys A, Rauseo M, Chen L, et al. Effort to breathe with various spontaneous breathing trial techniques: a physiologic meta-analysis. Am J Respir Crit Care Med. 2017;195:1477-85.

101. Tobin MJ. Extubation and the myth of "minimal ventilator settings". Am J Respir Crit Care Med. 2012;185:349-50.

102. Masip J, Peacock WF, Price S, Cullen L, Martin-Sanchez FJ, Seferovic P, et al. Indications and practical approach to non-invasive ventilation in acute heart failure. Eur Heart J. 2018;39:17-25.

103. Bendjelid K, Schutz N, Suter PM, Fournier G, Jacques D, Fareh S, et al. Does continuous positive airway pressure by face mask improve patients with acute cardiogenic pulmonary edema due to left ventricular diastolic dysfunction? Chest. 2005;127:1053-8.

104. Nava S, Gregoretti C, Fanfulla F, Squadrone E, Grassi M, Carlucci A, et al. Noninvasive ventilation to prevent respiratory failure after extubation in high-risk patients. Crit Care Med. 2005;33:2465-70.

105. Ferrer M, Sellarés J, Valencia M, Carrillo A, Gonzalez G, Badia JR, et al. Non-invasive ventilation after extubation in hypercapnic patients with chronic respiratory disorders: randomized controlled trial. Lancet. 2009;374:1082-8.

106. Pham T, Brochard L, Slutsky AS. Mechanical ventilation: state of the Art. Mayo Clin Proc. 2017;92:1382-400.

107. Schmidt GA, Girard TD, Kress JP, et al. Official executive summary of an American Thoracic Society/American College of Chest Physicians clinical practice guideline: liberation from mechanical ventilation in critically ill adults. Am J Respir Crit Care Med. 2017;195:115-9.

108. Hernández G, Vaquero C, Colinas L, et al. Effect of postextubation highflow nasal cannula versus noninvasive ventilation on reintubation and postextubation respiratory failure in high risk patients: a randomized clinical trial. JAMA. 2016;316:2047-8.

109. Carrie C, Bui HN, Gerbaud E, Vargas F, Hilbert G. Myocardial ischaemia and weaning failure: is angioplasty the heart of the problem? Intensive Care Med. 2011;37:1223-4.

110. Boussarsar M, Besbes L, Gamra H, Nouira S, Elatrous S, Betbout F, et al. Successful weaning from mechanical ventilation following balloon mitral commissurotomy. Intensive Care Med. 1997;23:889-92.

111. Koroneos A, Dedeilias P, Routsi C, Kotanidou A, Andrianakis I, Floros I, et al. Coronary artery bypass graft surgery for persistent weaning failure. Intensive Care Med. 2005;31:491-2.

112. Mantziari L, Kaushik G, Senguttuvan NB, Sharma R. Cardiac resynchronization therapy for critically ill patients with left ventricular systolic dysfunction. Int J Cardiol. 2013;163:141-5.

\section{Submit your manuscript to a SpringerOpen ${ }^{\circ}$ journal and benefit from:}

- Convenient online submission

- Rigorous peer review

- Open access: articles freely available online

- High visibility within the field

- Retaining the copyright to your article

Submit your next manuscript at springeropen.com 